\title{
Climate Change, Deforestation, and the Fate of the Amazon
}

Yadvinder Malhi, ${ }^{1}$ * J. Timmons Roberts, ${ }^{1,2}$ Richard A. Betts, ${ }^{3}$ Timothy J. Killeen, ${ }^{4}$ Wenhong Li, ${ }^{5}$ Carlos A. Nobre ${ }^{6}$

${ }^{1}$ Environmental Change Institute, Oxford University Centre for the Environment, South Parks Road, Oxford OX1 3QY, UK.

${ }^{2}$ College of William and Mary, Williamsburg, VA 23187, USA. ${ }^{3}$ Met Office Hadley Centre, Exeter EX1 3PB, UK.

${ }^{4}$ Conservation International, Washington DC, 20036, USA. ${ }^{5}$ School of Earth and Atmospheric Sciences, Georgia Institute of Technology, Atlanta, GA 30332-0340, USA. ${ }^{6}$ Instituto Nacional de Pesquisas Espaciais, São Jose dos Campos, SP, Brazil.

*To whom correspondence should be addressed. E-mail: yadvinder.malhi@ouce.ox.ac.uk

The forest biome of Amazonia is one of Earth's greatest biological treasures, and a major component of the Earth system. This century, it faces the dual threats of deforestation and stress from climate change. In this review, we summarize some of the latest findings and thinking on these threats, explore the consequences for the forest ecosystem and its human residents, and outline options for the future of Amazonia. We also discuss the implications of new proposals to finance preservation of Amazonian forests.

The forests of Amazonia (1) covered about 5.4 million $\mathrm{km}^{2}$ in 2001 , approximately $87 \%$ of their original extent (2), with $62 \%$ in Brazil. They host perhaps a quarter of the world's terrestrial species (3), and account for about 15\% of global terrestrial photosynthesis (4). Evaporation and condensation over Amazonia are engines of the global atmospheric circulation, having downstream effects on precipitation across South America, and further afield across the Northern Hemisphere (5, 6). Amazonian forests have been a significant and continuous part of earth system functioning since the Cretaceous (7).

By 2001, about 837,000 $\mathrm{km}^{2}$ of Amazonian forests had been cleared (2), with 1990s gross rates being about 25,000 $\mathrm{km}^{2}$ year ${ }^{-1}(8)$. Clearance is concentrated in the "arc of deforestation" on the southern and eastern margins, driven primarily by expansion of cattle and soybeans production, and along the Andean piedmont. Amazonia lies inside nine nations, but $80 \%$ of deforestation has been in Brazil (2), and $70 \%$ of that provoked by cattle ranching. Over 1988-2006, deforestation rates in Brazilian Amazonia averaged 18,100 $\mathrm{km}^{2}$ year $^{-1}$, recently reaching 27,400 $\mathrm{km}^{2}$ year $^{-1}$ in 2004. Brazilian deforestation rates had halved by 2006 to about $14,000 \mathrm{~km}^{2}$ year $^{-1}$, because of a combination of falling prices for soya, increased strength of the Brazilian currency, and active Brazilian government intervention (9). Roughly $6 \%$ of deforested land has remained in cropland, $62 \%$ in pastures and $32 \%$ in regrowing vegetation (10). The overall direct footprint of human activity in Amazonia is much greater than deforestation alone, and includes logging, hunting, and fire leakage (see supporting online text).

\section{Global Drivers of Amazonian Climate Change}

In recent decades the rate of warming in Amazonia (11) has been about $0.25{ }^{\circ} \mathrm{C}$ decade $^{-1}$. Under mid-range GHG emission scenarios, temperatures are projected to rise $3.3^{\circ} \mathrm{C}$ (range $1.8-5.1^{\circ} \mathrm{C}$ ) this century, slightly more in the interior in the dry season (12), or by up to $8^{\circ} \mathrm{C}$ if significant forest dieback affects regional biophysical properties (13). At the end of the last glacial period, Amazonia warmed (14) at only $\sim 0.1^{\circ} \mathrm{C}$ century ${ }^{-1}$.

Changes in precipitation, particularly in the dry season, are probably the most critical determinant of the climatic fate of the Amazon. There has been a drying trend in northern Amazonia since the mid-1970s, and no consistent multidecadal trend in the south (15), but some global climate models (GCMs) project significant Amazonian drying over the 21st century. Pacific sea surface temperature (SST) variation, dominated by the El Niño-Southern Oscillation (ENSO), is particularly important for wet-season rainfall: El Niño events (warm eastern Pacific) suppress convection in northern and eastern Amazonia. However, dry-season rainfall is strongly influenced by the tropical Atlantic north-south SST gradient; intensification of the gradient (warming of northern SSTs relative to the south) shifts the Intertropical Convergence Zone northwards (interannual time scales) and strengthens the Hadley Cell circulation (longer time scales), enhancing the duration and intensity of the dry season in much of southern and eastern Amazonia (16), as occurred in 2005. Interannual variability in the Atlantic gradient is influenced by remote forcing such as ENSO and the North Atlantic Oscillation, as well as by variations in evaporation induced by strengthening/weakening of the local trade winds (17). On longer time scales changes tropical Atlantic SSTs may be influenced by changes in the north Atlantic, such as changes of the thermohaline circulation driven by subpolar 
melting (18), or a warmer north Atlantic associated with warmer northern hemisphere continents.

\section{Forest Influences on Regional and Global Climate}

Amazonian forests have a substantial influence on regional and global climates. Hence their removal via deforestation can itself be a driver of climate change, and a positive feedback on externally forced climate change. They store $120 \pm 30$ PgC in biomass carbon (19), of which 0.5 PgC year ${ }^{-1}$ (0.3-1.1) were released through deforestation in the 1990s (10). Similar or greater amounts may be held in soil carbon, but these are less vulnerable to loss following deforestation (20). In addition, forest plot studies suggest that intact forests are a carbon sink ( 0.6 PgC year $\left.{ }^{-1}\right)$ (21), particularly in more fertile western Amazonia. The existence of this sink is debated (22), but is strongly supported by a recent reevaluation of global sources and sinks of atmospheric carbon dioxide (23). It may be driven by enhanced productivity associated with $\mathrm{CO}_{2}$ fertilization, changes in

light regime or other factors not yet identified (24).

The extraction of soil water by tree roots up to $10 \mathrm{~m}$ deep, and its return to the atmosphere (a "transpiration service”) is perhaps the most important regional ecosystem service. Basin-wide, 25 to $50 \%$ of rainfall is recycled from forests (25), but this effect is particularly important in regions where most precipitation is derived from local convection (see below). Moderate and localized deforestation may locally enhance convection and rainfall, but large-scale forest loss tends to reduce rainfall (26), the magnitude of reduction being dependent on how regional circulation of atmospheric moisture is affected. Some model studies suggest that the regional forest-climate system may have two stable states: removal of 30 to $40 \%$ of the forest could push much of Amazonia into a drier climate regime (27). Dry season rainfall, the most critical for determining vegetation patterns, is more often driven by locally generated convection, and may be more strongly affected by deforestation.

Loss of forest also results in (i) decreased cloudiness and increased insolation, (ii) increased land surface reflectance, approximately offsetting the cloud effect (28), (iii) changes in the aerosol loading of the atmosphere from a hyperclean "green ocean" atmosphere to a smoky and dusty continental atmosphere that can modify rainfall patterns (29), and (iv) changes in surface roughness and hence wind speeds and the large-scale convergence of atmospheric moisture that generates precipitation (13).

\section{Risks of Amazon Forest Loss Due to Global Climate Change}

Risks of a drying climate. The climate models employed in the 2007 Intergovernmental Panel on Climate Change (IPCC) Fourth Assessment Report (12) show no consistent trend in annual, Amazon-wide rainfall over the $21^{\text {st }}$ century, but a significant tendency to less dry season rain in the east, and more rain in the west and in the wet season (Fig. 1). Taking the ensemble of 23 IPCC models as a crude metric of probabilities, some intensification of dry seasons is about 80\% probable in the southeast Amazon and Guyanas, 70\% in the east, $60 \%$ in the centre, and 30\% in the west (Fig. 1A). The probabilities of more significant decline are slightly lower: $70 \%$ in the northeast, $60 \%$ in the Guyanas, $50 \%$ in the east, $40 \%$ in the centre, $20 \%$ in the west. The probabilities of severe decline in dry season rainfall are $50 \%$ in the southeast, $30 \%$ in the Guyanas and east, $10 \%$ in the centre and west. This metric is not ideal, as models may share systematic biases, vary in their ability to represent current Amazonian climates, most underestimate rainfall, and most do not incorporate the climatic feedbacks from forest loss; therefore a more careful evaluation of model ability to capture key elements of Amazonian climate variability is needed. When the effects of rising temperatures on evapotranspiration are included, almost all models indicate increasing seasonal water deficit in eastern Amazonia (30). This drying becomes more severe with greater magnitudes of global warming, and is exacerbated by ecosystem feedbacks such as forest die-back and reduced transpiration in remaining forests (13).

The zone of highest drought risk (southeast and east) is also the zone of most active deforestation (Fig. 2).

Deforestation-driven changes in precipitation may be strongest in the eastern dry corridor, $700 \mathrm{~km}$ inland from the coast, where geographical positioning results in oceangenerated squall lines passing through the region at night and being unable to trigger much rainfall (31), leaving a greater fraction of precipitation being locally generated. This area includes important agricultural and ranching frontiers that are experiencing high levels of deforestation.

In contrast, the northwestern Amazon is least likely to experience major drought. The high precipitation in this region is controlled by moisture convergence forced by the Andes, although it may be vulnerable to reduced precipitation recycling upwind in eastern Amazonia. This region hosts the highest biodiversity, and has been least affected by historical climate variability and land use.

The Andean flank of the Amazon has exceptional rates of biodiversity, adjoins the most biodiverse regions of lowland Amazonia, and also hosts a number of orographic wet-spots in otherwise dry areas (32). As conditions warmed at the end of the last ice age, the Andes acted as refugia for many "lowland" (now exclusively Andean) tree species that were ill-adapted to warming temperatures (33). Andean ecosystems have their own form of vulnerability, however: the cloud forests between 1500 and 3000 m elevation are susceptible to drying as cloud levels rise in the face of warming 
temperatures (34), and higher elevation restricted endemics would be particularly vulnerable.

Resilience of Amazonian forest ecosystems. Understanding of Amazonian forest processes has greatly advanced through the recent Large-Scale Biosphere-Atmosphere programme in Amazonia (LBA) (35). There is mounting evidence from artificial drought experiments (36), flux towers, and satellite remote sensing of forest greenness (37) that intact Amazonian forests are more resilient (though not invulnerable) to climatic drying than is currently represented in vegetation-climate models. First, dry season water supply is greatly enhanced by root systems accessing deep soil water, and redistributing it into the surface soil through the process of hydraulic lift, enabling the whole forest ecosystem to maintain high transpiration and photosynthesis rates (38). Second, plant acclimation to higher temperatures may limit detrimental effects below $45^{\circ} \mathrm{C}$ [when proteins begin to denature (39)], though selective advantage by favored species may cause changes in community composition, as occurred at the last glacial-interglacial transition (33). Finally, rising $\mathrm{CO}_{2}$ may improve plant water use efficiencies, and offset the negative transpiration effects of rising temperatures. Southern Amazonia was significantly drier as recently as the early-mid Holocene, yet the region seems to have remained largely forested (33).

\section{The Interaction Between Human Pressures and Forest Resilience}

The speed and magnitude of current human pressures on forests are affecting forest resilience. Forests close to edges are vulnerable to elevated dessication, tree mortality (40), and fire impacts. Rainforests may become seasonally flammable in dry years, but without anthropogenic ignition sources fire is a rare occurrence. Hence fire has been a weak evolutionary selective force, and as a result many tree species lack adaptations that allow them to survive even low-intensity fires (41).

Fire use for land management is nearly ubiquitous in rural Amazonia. Approximately 28\% of the Brazilian Amazon faces incipient fire pressure, being within $10 \mathrm{~km}$ of a fire source (42). Logging and forest fragmentation also increase the flammability of forests by providing substantial combustion material, opening up the canopy and drying the understory and litter layer, and greatly increasing the amount of dry fire-prone forest edge. This synergism between fragmentation and fire is becoming increasingly important, with $20-50,000 \mathrm{~km}^{2}$ of new forest edge being created annually in Brazilian Amazonia alone (43). Once burnt, a forest becomes more vulnerable to further burns (44), loses many primary forest species, and decreases sharply in biomass (41). A tipping point may be reached when grasses can establish in the forest understory, providing a renewable source of fuel for repeated burns.

In scenarios of increased drying, it is possible to see this logging, fragmentation, dessication and repeated burning as a likely fate for many of Amazonia's forests. The 2005 drought provides evidence of this in southwest Amazonia: remote forests remained fairly unaffected, but there was substantial penetration of fires from agricultural areas into surrounding, temporarily flammable forests (45).

Despite the very recent slowdown in deforestation rates, there is potential for extensive deforestation in Amazonia, as more roads (both official and unplanned) are built through its core and connect across to Pacific ports, and as international demand for tropical timber, soybeans and free-range beef continues to grow, particularly from rapidly expanding Asian economies (2, 46, 47). Existing pressures might be exacerbated by accelerating worldwide demand for biofuels. Current plans for infrastructure expansion and integration could reduce forest cover from 5.4 million $\mathrm{km}^{2}$ (2001, 87\% of original area) to 3.2 million $\mathrm{km}^{2}$ (53\%) by 2050 (2) (Fig. 2A). This exceeds the likely threshold for rainfall maintenance, and would emit $32 \pm 8 \mathrm{Pg}$ of carbon. Deforestation will be more concentrated in the south and east, with $>50 \%$ forest loss, and along the Andean piedmont, isolating the warming lowlands from potential biotic refuges in the cooler mountains (46). In this scenario the northwestern Amazon is protected by its remoteness and wetness, but longer term, this region is also vulnerable to hydrocarbon exploration and oilpalm plantations that are suitable for wet climates and acidic soils and have already replaced many of Asia's tropical rainforests (46). Drying of Amazonia, whether caused by local or global drivers, could greatly expand the area suitable for soy, cattle and sugarcane, accelerating forest disappearance.

\section{Planning for Climate Change}

The probability of significantly enhanced drought (Fig. 1B) under mid-range greenhouse gas emissions scenarios ranges from $>60 \%$ in the southeast to $<20 \%$ in the west. The severity of this potential threat merits planning for development, conservation and adaptation in all regions. Even if the drought does not come, a well-conceived and implemented plan will have built resilience into the Amazon social ecological system.

It is almost inevitable that substantial further conversion of forest into agricultural and pasture lands will occur as part of the economic development of Amazonian countries $(2,46)$. The danger is that degradation of ecosystem services could push some subregions into a permanently drier climate regime, and greatly weaken the resilience of the entire region to possible large-scale drought driven by SST changes. Hence the challenge is to manage the economic development of 
Amazonia so that it occurs where appropriate and sustainable, in a way that maintains the inherent climatic resilience that the intact forest provides. Simultaneously, this would preserve the region's carbon store and sink and its exceptional biodiversity, contributing both towards mitigating global warming and assisting that biodiversity to adapt to climate change.

Key aspects of such a plan for Amazonia could include

1. Keeping the total extent of deforestation safely below possible climatic threshold values (about 30-40\% cleared), in a matrix that includes large protected areas with limited fragmentation, and managed landscapes that maintain sufficient forest cover and landscape connectivity to preserve species migration corridors and forest transpiration services.

2. Controlling fire use through both education and regulation, probably for net economic benefit.

3. Maintaining broad species migration corridors in ecotonal areas that are most likely to show early signals of climate impacts, such as those between forest and savanna, between lowlands and the Brazilian and Guyana shield uplands, between the Andean piedmont and montane forest, and between montane forest and highland Andean grasslands.

4. Conserving river corridors to act as humid refugia and migration corridors for terrestrial ecosystems, sedimentation buffers, and as refugia for aquatic systems. Many of the southern tributaries of the Amazon river run from dry fringes to the wet core, and could assist the migration of wet-adapted species.

5. Keeping the core northwest Amazon largely intact as a biological refuge that hosts the highest biodiversity and is the least vulnerable to climatic drying.

Is such a plan feasible? With the expansion of protected areas and effective legal enforcement of private land-use, the projections of loss of $47 \%$ of original forest area by 2050 could be reduced to $28 \%$ loss (2), avoiding $~ 17$ PgC emissions (Fig. 2B). Recent developments suggest that such good governance is achievable: details of the role that can be played by protected areas, indigenous peoples, smallholders, agroindustries and governments are discussed in the supporting online text.

\section{Financing a Climate-Resilience Plan for Amazonia}

A plan for keeping Amazonia from ecological and climatic decline faces several challenges: the drive of globalizing market forces, insufficient financial resources, provision of open access to information, limited technical and governance capacity, and ineffective enforcement of rule of law. In particular, new financial incentives are needed to act as a countervailing force to the economic pressures for deforestation.

Such incentives are now a serious possibility, via the international markets in carbon spawned by the Kyoto
Protocol, such as the European Union's Emissions Trading System. Several current proposals to amend the Kyoto Protocol call for rainforest nations to be paid for reducing emissions from deforestation in developing countries (REDD), either through international carbon markets or a voluntary fund (48-50). Tropical forest carbon credits have particular value within a climate mitigation strategy, as they bring additional direct climatic services [cloud formation and precipitation, local cooling by evapotranspiration(28)], as well as other ecosystem services such as biodiversity conservation, watershed protection, and pollination.

These plans have the potential to shift the balance of underlying economic market forces that currently favor deforestation (45), by raising billions of dollars for the ecosystem services provided by rainforest regions, but will require exceptional planning, execution and long-term follow-through. Such resources could support the expansion of capacity in forest monitoring (e.g., freely available satellite-based monitoring as already achieved by Brazil), and improved governance and rule-of-law in frontier regions, but in particular would need to ensure that they bring benefits and incentives (e.g., improved social services like health and education) to the individuals and groups making decisions about Amazon land-use on a daily basis, be they indigenous peoples, rural subsistence dwellers, smallholder migrants or large private landholders.

The interaction between global climate change and regional deforestation may make Amazonian forests vulnerable to large-scale degradation. Ironically, it is also this linkage between the global (carbon sequestering) ecosystem service, for which the world may be more willing to pay, and regional (transpiration) services that maintain the region's climate, that provides an opportunity to sustain the climatic resilience of Amazonia while contributing towards its conservation and development.

The next few years represent a unique opportunity, perhaps the last, to maintain the resilience, biodiversity and ecosystem services of Amazonia in the face of a medium threat of significant drying and a high threat of significant deforestation. The best climate, ecological, economic and social science will be needed to develop, implement and monitor effective policy responses for securing the region's future. The other key requirement is political will at the local, national and international levels (51).

\section{References and Notes}

1. Here defined as the Legal Amazon in Brazil and the Amazon river watershed and Guyanas region outside of Brazil.

2. B.S. Soares et al., Nature 440, 520 (2006).

3. R. Dirzo, P. H. Raven., Annu. Rev. Env. Res. 28, 137 (2003). 
4. C. B. Field, M. J. Behrenfeld, J. T. Randerson, P. Falkowski, Science 281, 237 (1998).

5. N. Gedney, P. J. Valdes Geophys. Res. Lett. 27, 3053 (2000)

6. D. Werth, R. Avissar., J. Geophys. Res.-Atm. 107, 8087 (2002).

7. M. Maslin, Y. Malhi, O. Phillips, S. Cowling, Trans. Inst. British Geogr. 30, 477 (2005).

8. F. Achard et al., Science, 297, 999 (2002)

9. D. Nepstad et al., Conserv. Biol. 20, 65 (2006).

10. N. Ramankutty et al., Global Change Biol. 13, 51 (2007).

11. Y. Malhi, J. Wright., Philos. Trans. Roy. Soc. Lond. B Biol. Sci. 359, 311 (2004).

12. J. H. Christensen et al., in Climate Change 2007: The Physical Science Basis. Contribution of Working Group I to the Fourth Assessment Report of the Intergovernmental Panel on Climate Change, S. D. Solomon et al., Eds. (Cambridge Univ. Press, Cambridge and New York, 2007), chap. 11.

13. R. A. Betts et al., Theor. Appl. Clim. 78, 157 (2004).

14. M B. Bush, M. R. Silman, D. H. Urrego, Science 303, 827 (2004).

15. J.A. Marengo., Theor. Appl. Clim. 78, 79 (2004).

16. W.H. Li, R. Fu, R.E. Dickinson, J. Geophys. Res. 111, no D02111, doi:10.1029/2005JD006355 (2006).

17. P. Chang, R. Saravanan, L. Ji, Geophys. Res. Lett., 30, 1501 (2003)

18. B.W. Dong, R.T. Sutton., Geophys. Res. Lett. 29, 1728 (2002).

19. Y. Malhi et al., Global Change Biol. 12, 1107 (2006).

20. K.W. Holmes et al., Global Biogeochem. Cycles, 20, GB3004 (2006)

21. T.R. Baker et al., Phil. Trans. Roy. Soc. Lond. B Biol. Sci. 359, 353 (2004)

22. S.J. Wright, Trends Ecol. Evol., 20, 553 (2005)

23. B.B. Stephens et al., Science 316, 1732 (2007)

24. S.L. Lewis et al., Phil. Trans. Roy. Soc. Lond. B Biol. Sci. 359, 421 (2004)

25. E. A. B. Eltahir, R. L. Bras., Q. J. R. Meteorol. Soc. 120, 861 (1994).

26. S. B. Roy, R. Avissar, J. Geophys. Res. 107, 8037 (2002).

27. M. D. Oyama, C. A. Nobre, Geophys. Res. Lett. 30, 2199 (2003).

28. G. Bala et al., Proc. Natl. Acad. Sci. U.S.A. 104, 6550 (2007).

29. M.O. Andreae et al., Science 303, 1337 (2004).

30. L. F. Salazar, C. A. Nobre, and M.D. Oyama, Geoph. Res. Let., 34, L09708, (2007)

31. M. Garstang, H. L. Massie Jr., J. Halverson, S. Greco, J. Scala, Mon. Weather Rev. 122, 608 (1994).

32. T.J. Killeen, M. Douglas, T. Consiglio, P.M. Jorgensen, J. Mejia, J. Biogeogr. 34, 1357 (2007)
33. F.E. Mayle, D.J. Beerling, W.D. Gosling, M.B. Bush, Phil. Trans. Roy. Soc. Lond. B Biol. Sci. 359, 499 (2004).

34. P. Foster., Earth-Sci. Rev. 55, 73 (2001).

35. LBA website: http://lba.cptec.inpe.br/lba/site

36. R.A. Fisher et al., Global Change Biology, 13, 1 (2007)

37. A.R. Huete et al., Geophys. Res. Lett., 33, L06405 (2006)

38. R.S. Oliveira, T.E. Dawson, S.S.O. Burgess, D.C. Nepstad, Oecologia 145, 354 (2005).

39. T.D. Sharkey, S.M. Schrader, High Temperature Stress, in Physiology and Molecular Ecology of Stress Tolerance in Plants (Kluwer Academic Publishers, Netherlands 2004)

40. W.F. Laurance et al., Science 278, 1117 (1997).

41. J. Barlow, C.A. Peres., Phil. Trans. Roy. Soc. Lond. B Biol. Sci. 359, 367 (2004).

42. P. Barreto et al., Human Pressure on the Brazilian Amazon Forests (WRI: Washington DC, Imazon: Belém, 2006).

43. M.A. Cochrane, W.F. Laurance, J. Tropical Ecol., 18, 311 (2002)

44. M.A. Cochrane et al., Science 284, 1832 (1999).

45. L.E.O.C. Aragão et al., Geophys. Res. Lett. 34, L07701 (2007).

46. T.J. Killeen, Advances in Applied Biodiversity Science No. 7,. Washington DC: Center for Applied Biodiversity Science, Conservation International (2007).

47. A.A.C. Alencar, L.A. Solorzano, D.C. Nepstad, Ecol. Appl. 14, S139 (2004).

48. M. Santilli et al., Clim. Change 71, 267 (2005).

49. R.E. Gullison et al., Science 316, 985 (2007).

50. P. Moutinho, S. Schwartzman, Tropical Deforestation and Climate Change (IPAM, Belem, Brazil, 2005).

51. This paper is based largely on the conference "Climate Change and the Fate of the Amazon,” held at Oriel College, University of Oxford, March 23-25, 2007 and funded by the James Martin 21st Century School, the Environmental Change Institute, and the Centre for Brazilian Studies, University of Oxford. Conference presentations are available at http://www.eci.ox.ac.uk/news/events/070320presentations. php. We thank all participants at the conference, in particular E. Boyd, M. Gloor, P. Harris, J. Lloyd, J. Marengo, D. Nepstad, O. Phillips, and B. Soares, for their comments on this manuscript. Y.M. is supported by the Jackson Foundation and J.T.R. by the James Martin 21st Century School. We thank D. Maniatis and P. Zelazowski for assistance in manuscript preparation. We acknowledge the Coupled Model Intercomparison Project (CMIP) and the international modeling groups for providing their data for analysis. 


\section{Supporting Online Material}

www.sciencemag.org/cgi/content/full/1146961/DC1

SOM Text

References and Notes

25 June 2007; accepted 11 October 2007

Published online 22 November 2007;

10.1126/science. 1146961

Include this information when citing this paper.

Fig. 1. A metric of the probability of enhanced drought in Amazonia: the proportion of 23 climate models that show a decline in rainfall between 1980 to 1999 and 2080 to 2099 under mid-range (A1B) global greenhouse gas emissions scenarios. (A) Any decline (rainfall decline $>0 \%$ ); (B) significant decline (rainfall decline $>20 \%$ ); severe decline (rainfall decline $>50 \%$ ). Dry season rainfall is particularly important. Left column: December-January-February (dry season in north); right column: June-July-August (dry season in central and southern Amazonia).

Fig. 2. The potential overlap between deforestation and climate change. Potential loss in forest cover (brown) by 2050 under (A) business as usual and (B) increased governance scenarios [derived from (2)], superposed on mean projection of precipitation change in June-July-August (dry season in all but the northern edge of Amazonia) by the late 21st century. Precipitation scenarios are from mid-range (A1B) global greenhouse gas emissions scenarios, from the 21 climate models employed in IPCC Fourth Assessment Report [extracted and modified from (15)]. The projection of precipitation change is correlated with the probability of drought (Fig. 1). 

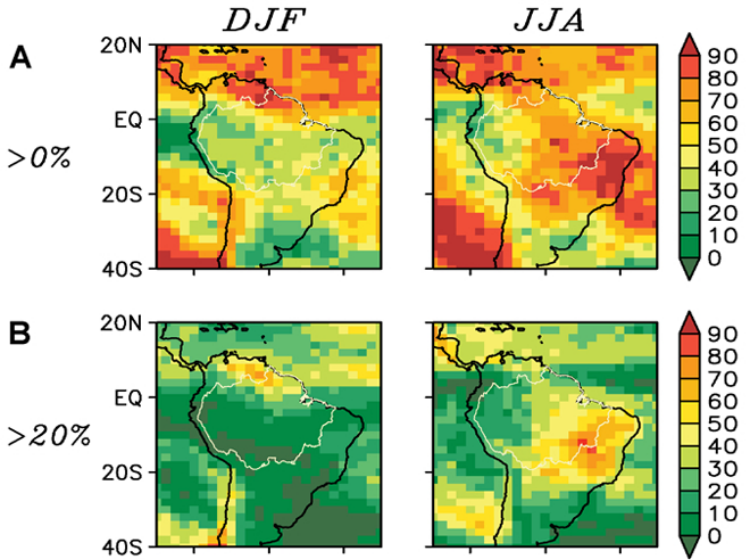

C

$>50 \%$
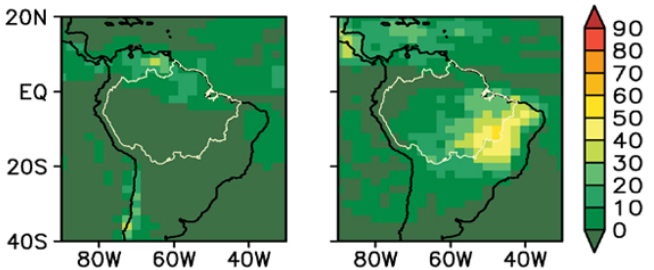


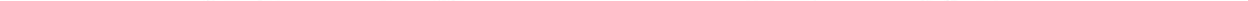

